\title{
Chilling Injury of Tropical Horticultural Commodities
}

\author{
Chien Yi Wang \\ Horticultural Crops Quality Laboratory, Beltsville Agricultural Research Center, Agricultural Research Service, \\ U.S. Department of Agriculture, Beltsville, MD 20705-2350
}

Most tropical horticultural commodities are sensitive to chilling temperatures. Therefore, chilling injury (CI) is a serious problem in the postharvest handling of tropical horticultural commodities. From the standpoint of CI, we can classify all horticultural crops into three categories: A) chilling resistant; B) chilling sensitive; and C) slightly chilling sensitive. The storage life of commodities in group $\mathrm{A}$ is inversely related to storage temperature. The lower the storage temperature, the longer the storage life, as long as the temperature is not below the freezing point. The storage life of commodities in group B increases with decreasing storage temperature down to a certain point; then, storage life decreases with any further temperature decrease. This point is called the critical chilling temperature. It usually occurs at $\approx 10$ to $13 \mathrm{C}$. Most crops of tropical or subtropical origin are chilling sensitive and belong to group $\mathrm{B}$. The critical chilling temperature in group C plants is lower than that in group B plants. It usually occurs at $\approx 3$ or $4 \mathrm{C}$. Some temperate crops are in this group, such as 'McIntosh' apples (Malus domestica Borkh.). About one-third of all fruits and vegetables in U.S. markets are susceptible to CI. Most of the susceptible crops are of tropical or subtropical origin.

\section{SYMPTOMS IN TROPICAL COMMODITIES}

CI symptoms vary with commodities. Some common CI symptoms in tropical horticultural commodities are pitting, discoloration, watersoaked appearance, internal breakdown, failure to ripen, loss of flavor and aroma, and decay (Hardenburg et al., 1986). Symptom development depends not only on species and cultivars, but also on maturity, types of tissues, and other environmental factors, such as storage humidity. Pitting, circular or irregular-shaped pits on the fruit surface, is the most common form of CI and the first CI symptom in many tropical horticultural commodities. Surface pitting can occur on beans (Phaseolus vulgaris L.), citrus fruits [Citrus sinensis (L.) Osbeck], cucumbers (Cucumis sativus L.), eggplants (Solanum melongena L.), melons (Cucumis melo L.), okra (Hibiscus esculentus L.), papayas (Carica papaya L.), pomegranates (Punica granatum L.), sweet peppers (Capsicum annuum L.), sweetpotatoes [Ipomea batatas (L.) Lam.], and tamarillos [Cyphomandra betacea (Cav.) Sendt.]. Failure to ripen is another common CI symptom in tropical and subtropical crops; it can occur in avocados (Persea americana Mill.), bananas (Musa spp.), mangos (Mangifera indica L.), melons, papayas, sapodilla (Achras sapota L.), and tomatoes (Lycopersicon esculentum Mill.). There are CI symptoms that are specific to individual commodities; some examples include subepidermal brown streaking of vascular tissues in bananas, membranous staining in lemons [Citrus limon (L.) Burm. f.], and mahogany browning in potatoes (Solanum tuberosum L.).

\section{RESPONSE OF TROPICAL COMMODITIES TO CHILLING TEMPERATURE}

There are two schools of thought concerning the response of chilling-sensitive commodities to chilling temperature. According to the first concept, a single, unifying primary response to chilling temperature exists in all chilling-sensitive species. This primary response would lead to secondary events that include various physiological and biochemical alterations. These alterations would eventually lead to the development of a variety of CI symptoms. Several events have been proposed as possible candidates for a primary response, such as a transition in membrane lipids; an alteration in the kinetics or substrate specificity of a regulatory enzyme; a change in the cytoskeletal structure; or an increase in the cytosolic $\mathrm{Ca}$ (Raison and Orr, 1990). However, there is still no conclusive proof to substantiate or pinpoint such events. The second concept holds that CI originates from a multitude of responses to low temperature. Considering the diversity of tropical horticultural crops in structure and in expression of CI symptoms, proponents of this concept question that a single universal primary event can set in motion a chain of events cascading into a wide range of CI symptoms (Lyons and Breidenbach, 1987; Shewfelt, 1992; Wade, 1979). The second concept suggests that there are multiple responses over a wide range of conditions.

\section{IMPORTANCE OF ALLEVIATING CI IN TROPICAL COMMODITIES}

Postharvest losses resulting from CI are probably greater than has been recognized. Quite often, CI symptoms may not be apparent while the produce is still in cold storage; the symptoms show up later, only after the produce has been transferred to market where the temperature is higher. At the market, a substantial portion of losses resulting from CI may be mistakenly ascribed to pathogen-induced or ripening disorders.

Low-temperature storage is considered to be the most effective method for maintaining the quality of most fruits and vegetables because low temperature retards respiration, ethylene production, ripening, senescence, undesirable metabolic changes, and decay (Hardenburg et al., 1986). Unfortunately, for CI-sensitive crops, such as tropical horticultural commodities, low-temperature storage is often more detrimental than beneficial. Therefore, chilling-sensitive crops do not always benefit from refrigeration. However, if these chilling-sensitive commodities are not refrigerated, they tend to break down rapidly and have a short storage life. This dilemma results in tremendous postharvest losses for tropical horticultural commodities. It is apparent that alleviating CI in these crops is vitally important.

\section{POSTHARVEST TECHNIQUES FOR REDUCING CI}

Postharvest researchers have taken several approaches to lessen chilling-induced injury. These postharvest techniques include temperature conditioning, intermittent warming, controlled-atmosphere storage, chemical treatments, and growth regulator application. The first three techniques involve manipulating and modifying the storage environment, while the other methods involve directly treating the commodities. These techniques reduce CI by either increasing the tolerance of commodities to chilling temperature or retarding the development of CI symptoms.

\section{Temperature conditioning}

Prestorage temperature can significantly affect the susceptibility of tropical commodities to CI (Hatton, 1990; Paull, 1990). In lowtemperature conditioning, exposing commodities to temperatures slightly above the critical chilling range can increase their tolerance to chilling exposure. This low-temperature conditioning is effective in reducing $\mathrm{CI}$ in the following tropical and subtropical crops: cucumbers, eggplants, grapefruit (Citrus paradisi Macfad.), lemons, limes [Citrus aurantifolia (Christm.) Swingle], mangos, papayas, sweet peppers, tomatoes, and zucchini squash (Cucurbita pepo L.). Temperature conditioning can be performed as a single step or in multiple steps. Usually, multistep conditioning is more effective. For example, eggplants conditioned at $15 \mathrm{C}$ for 2 days followed by 1 day at $10 \mathrm{C}$ had less pitting (after storage at 6.5C) than those conditioned for 2 days at 15C alone (Nakamura et al., 1985). In bananas, gradually decreasing the temperature in $3 \mathrm{C}$ steps from 21 to $5 \mathrm{C}$ at 12 -h intervals resulted in the least $\mathrm{CI}$ compared to a $5 \mathrm{C}$ decrease every $24 \mathrm{~h}$, an $8 \mathrm{C}$ decrease every $36 \mathrm{~h}$, or a single change from 21 to 5C (Pantastico et al., 1967). Low-temperature conditioning has been associated with maintaining high levels of phospholipids in membranes, increasing the degree of unsaturation in membrane fatty acids, suppressing the increase in the 
sterol : phospholipid ratio, and increasing polyamine, squalene, and long-chain aldehyde concentrations. All these factors may contribute to reducing $\mathrm{CI}$.

Brooks and McColloch first reported using prestorage high-temperature conditioning to reduce $\mathrm{CI}$ in 1936 . They found that conditioning at $38 \mathrm{C}$ for 17 to $22 \mathrm{~h}$ significantly reduced pitting in grapefruit stored at 4.5C. Since then, other tropical fruits and vegetables, including cucumbers, lemons, mangos, pomelos [Citrus grandis(L.) Osbeck], sweetpotatoes, tomatoes, and watermelons [Citrullus lanatus (Thunb.) Mansf.], have also been found to benefit from high-temperature conditioning. Ben-Yehoshua et al. (1987) found that heat treatment increased antifungal materials, such as scoparone and umbelliferone, and reduced decay and $\mathrm{CI}$ in lemon and pomelo fruits. Curing sweetpotatoes at high temperatures promotes the healing of cuts and bruises, reduces moisture loss, and provides protection against invasion by microorganisms during subsequent cold storage. Protection against $\mathrm{CI}$ by prestorage heat treatment in tomatoes is related to the accumulation of heat-shock proteins (Lurie and Klein, 1991).

\section{Intermittent warming}

Intermittent warming is the interruption of low-temperature storage with one or more periods of warm temperature. This treatment must be applied before CI becomes irreversible. Otherwise, if the critical time at chilling temperature has been exceeded and CI has progressed beyond recovery, then raising the temperature would only accelerate degradation. Therefore, timing the treatment is critical and detecting CI early is important. Intermittent warming has been used successfully in commercial operations for lemon fruit in Israel (Cohen, 1988). CI in lemons can be reduced by warming the fruit for 7 days at $13 \mathrm{C}$ after every 21 days in cold storage at 2C. Market quality of 'Eureka' and 'Villa Franca' lemons can be maintained for at least 6 months by using this storage technique (Cohen et al., 1983). For crops with a short storage life, such as cucumbers, sweet peppers, and zucchini squash, intermittent warming must be applied earlier and more frequently (Kramer and Wang, 1989; Wang and Baker, 1979). A popular hypothesis for intermittent warming states that raising the temperature in the middle of chilling exposure usually induces higher metabolic activities and allows the tissue to metabolize excess intermediates or toxic materials accumulated during chilling (Pentzer and Heinze, 1954). Warming chilled tissues for short periods may also help to repair damage to membranes, organelles, or metabolic pathways and to replenish any substances that are depleted or are unable to be synthesized during chilling. Another hypothesis regarding the mechanism of intermittent warming states that shifting the temperature from low to high and then from high to low probably induces a rapid metabolic readjustment that increases polyunsaturated fatty acid synthesis (Wang, 1982). Fatty acid elongation and desaturation can occur when the temperature is changed from high to low (Fukushima et al., 1979). This change likely affects membrane fluidity and increases tolerance to low temperature.

\section{Controlled-atmosphere storage}

Controlled-atmosphere storage may be beneficial, detrimental, or ineffectual in reducing CI. Controlled-atmosphere storage is beneficial in preventing $\mathrm{CI}$ in avocados, grapefruit, okra, pineapples [Ananas comosus (L.) Merr.], and zucchini squash. In contrast, controlledatmosphere storage accentuates CI symptoms in cucumbers, limes, and sweet peppers. In some crops, such as lemons, papayas, and tomatoes, controlled-atmosphere storage does not seem to have any effect on their susceptibility to CI.

\section{Chemical treatments}

Chemicals reported to be effective in reducing $\mathrm{CI}$ include $\mathrm{Ca}$, ethoxyquin, sodium benzoate, 1-(2-(2,4-dichlorophenyl)-2-(2propenyloxylethyl)- $1 H$-imidazole) (imazalil), 2-(4-thiazolyl) benzimidazole (thiabendazole), mineral oil, safflower oil, vegetable oil, and squalene. Calcium apparently strengthens cell walls and cell membranes and helps tissues withstand chilling stress. It has reduced
CI in avocados (Chaplin and Scott, 1980), okra (Ilker and Morris, 1975), and tomatoes (Moline and Teasdale, 1981). Ethoxyquin and sodium benzoate are free-radical scavengers. Scavenging free radicals can reduce the peroxidation of unsaturated fatty acids in membrane lipids, thereby helping to maintain membrane integrity and reduce $\mathrm{CI}$. These free-radical scavengers are effective in reducing CI in cucumbers and sweet peppers (Wang and Baker, 1979). The fungicides imazalil and thiabendazole inhibit latent infections, reduce pitting, and delay peel senescence in oranges and grapefruit (McDonald et al., 1990; Schiffmann-Nadel et al., 1972). Mineral oil and safflower oil prevent chilling-induced underpeel discoloration of bananas (Jones et al., 1978). Vegetable oil delays CI in grapefruit (Aljuburi and Huff, 1984). These oils may have antitranspirant and antioxidant activities that reduce moisture loss and oxidative damage, thereby reducing CI. Squalene is a highly unsaturated C30 isoprene hydrocarbon. Nordby and McDonald (1990) found that squalene is a natural wax compound in grapefruit peel and applying additional squalene can effectively protect grapefruit from CI.

\section{Growth regulator application}

Growth regulators affect many biochemical and physiological processes in plant tissues. Their effect on these processes may in turn alter the chilling tolerance of tissues. Abscisic acid (ABA) has been studied extensively in relation to CI. ABA induces stomatal closure, reduces water loss, and prevents chilling-induced wilting of seedlings (Rikin and Richmond, 1976). ABA also stabilizes the microtubular network, suppresses ion leakage, and prevents the loss of reduced glutathione and membrane phospholipids (Rikin et al., 1979). ABA applications reduce CI of grapefruit (Kawada et al., 1979) and zucchini squash (Wang, 1991). Ethylene treatment reduces CI in 'Honey Dew' melons (Lipton and Aharoni, 1979), but increases CI in avocados (Chaplin et al., 1983). Since ethylene is a ripening hormone, the effect of ethylene on CI may be mediated through its effect on maturity and ripening. Several triazole plant growth regulators increase the tolerance of plants to CI (Asare-Boamah and Fletcher, 1986; Lee et al., 1985; Senaratna et al., 1988). Compounds such as $\beta-[(4-$ chlorophenyl)methyl]- $\alpha$-(1,1-dimethyl)-1H-1,2,4-triazole-1-ethanol (paclobutrazol), E-(p-chlorophenyl)-4,4-dimethyl-2-(1,2,4-triazol-1yl)-1-penten-3-ol (uniconazole), and 1-(4-chlorophenoxy)-3,3dimethyl-1-(1,2,4-triazol-1-yl)-2-butanone (triadimefon) may protect membrane components from oxidative damage during chilling by increasing the defense mechanism of tissues against free-radical attack. Polyamines are a group of polycationic organic compounds and are ubiquitous in cells. Postharvest treatments with exogenous polyamines increase internal polyamine levels and reduce CI in zucchini squash (Kramer and Wang, 1989). The reduction of CI by polyamines may be related to their antioxidant activity and stabilizing effect on membranes.

\section{CONCLUSIONS}

CI is responsible for substantial postharvest losses in tropical horticultural commodities. Although no method can completely eliminate CI, several approaches do show promise in alleviating this problem. These techniques reduce CI either by retarding the development of injury symptoms or by increasing the tolerance of commodities to chilling. The search for better techniques will continue, so that we can continue to improve the quality and reduce the postharvest losses of all tropical horticultural commodities.

\section{Literature Cited}

Aljuburi, H.J. and A. Huff. 1984. Reduction in chilling injury to stored grapefruit (Citrus paradisi Macf.) by vegetable oil. Sci. Hort. 24:53-58.

Asare-Boamah, N.K. and R.A. Fletcher. 1986. Protection of bean seedlings against heat and chilling injury by triadimefon. Physiol. Plant. 67:353-358.

Ben-Yehoshua, S., E. Barak, and B. Shapiro. 1987. Postharvest curing at high temperatures reduces decay of individually sealed lemons, pomelos, and other citrus fruit. J. Amer. Soc. Hort. Sci. 112:658-663.

Brooks, C. and L.P. McColloch. 1936. Some storage diseases of grapefruit. J. Agr. Res. 52:319-351. 
Chaplin, G.R. and K.J. Scott. 1980. Association of calcium in chilling injury susceptibility of stored avocados. HortScience 15:514-515.

Chaplin, G.R., R.B.H. Wills, and D. Graham. 1983. Induction of chilling injury in stored avocados with exogenous ethylene. HortScience 18:952-953.

Cohen, E. 1988. Commercial use of long-term storage of lemon with intermittent warming. HortScience 23:400.

Cohen, E., M. Shuali, and Y. Shalom. 1983. Effect of intermittent warming on the reduction of chilling injury of 'Villa Franca' lemon fruit stored at cold temperature. J. Hort. Sci. 58:593-598.

Fukushima, H., S. Nagao, and Y. Nozawa. 1979. Further evidence for changes in the level of palmitoyl-CoA desaturase during thermal adaptation in Tetrahymena pyriformis. Biochim. Biophys. Acta 572:178-182.

Hardenburg, R.E., A.E. Watada, and C.Y. Wang. 1986. The commercial storage of fruits, vegetables, and florist and nursery stocks. U.S. Dept. Agr., Agr. Hdbk. 66, Washington, D.C.

Hatton, T.T. 1990. Reduction of chilling injury with temperature manipulation, p. 269-280. In: C.Y. Wang (ed.). Chilling injury of horticultural crops. CRC Press, Boca Raton, Fla.

Ilker, Y. and L.L. Morris. 1975. Alleviation of chilling injury of okra. HortScience $10: 324$.

Jones, R.L., H.T. Freebairn, and J.F. McDonnell. 1978. The prevention of chilling injury, weight loss reduction, ripening retardation in banana. J. Amer. Soc. Hort. Sci. 103:219-221.

Kawada, K., T.A. Wheaton, A.C. Purvis, and W. Grierson. 1979. Levels of growth regulators and reducing sugars of 'Marsh' grapefruit peel as related to seasonal resistance to chilling injury. HortScience 14:446.

Kramer, G.F. and C.Y. Wang. 1989a. Reduction of chilling injury in zucchini squash by temperature management. HortScience 24:995-996.

Kramer, G.F. and C.Y. Wang. 1989b. Correlation of reduced chilling injury with increased spermine and spermidine levels in zucchini squash. Physiol. Plant. 76:479-484.

Lee, E.H., J.K. Byun, and G.L. Steffens. 1985. Increased tolerance of plants to $\mathrm{SO}_{2}$, chilling, and heat stress by a new GA biosynthesis inhibitor, paclobutrazol (PP333). Plant Physiol. 77(Suppl.):135.

Lipton, W.J. and Y. Aharoni. 1979. Chilling injury and ripening of 'Honey Dew' muskmelons stored at 2.5 or $5 \mathrm{C}$ after ethylene treatment at 20C. J. Amer. Soc. Hort. Sci. 104:327-330.

Lurie, S. and J.D. Klein. 1991. Acquisition of low-temperature tolerance in tomatoes by exposure to high-temperature stress. J. Amer. Soc. Hort. Sci. 116:1007-1012.

Lyons, J.M. and R.W. Breidenbach. 1987. Chilling injury, p. 305-326. In: J. Weichmann (ed.). Postharvest physiology of vegetables. Marcel Dekker, New York.

McDonald, R.E., W.R. Miller, and T.G. McCollum. 1990. Reducing chilling injury and decay of grapefruit by fungicides applied at high temperatures. HortScience 25:1084

Moline, H.E. and J. Teasdale. 1981. Some effects of calcium treatments on ripening rate and chilling injury of tomato fruit. Proc. 3rd Tomato Quality Wkshp., College Park, Md. p. 119-131.

Nakamura, R., A. Inaba, and T. Ito. 1985. Effect of cultivating conditions and postharvest stepwise cooling on the chilling sensitivity of eggplant and cucumber fruits. Sci. Rpt., Okayama Univ., Japan, Sci. Rpt. 66, p. 19-29.

Nordby, H.E. and R.E. McDonald. 1990. Squalene applied to grapefruit prevents chilling injury. HortScience 25:1094.

Pantastico, E.B., W. Grierson, and J. Soule. 1967. Chilling injury in tropical fruits: I. Bananas. Proc. Trop. Reg. Amer. Soc. Hort. Sci. 11:82-91.

Paull, R.E. 1990. Chilling injury of crops of tropical and subtropical origin, p. 17-36. In: C.Y. Wang (ed.). Chilling injury of horticultural crops. CRC Press, Boca Raton, Fla.

Pentzer, W.T. and P.H. Heinze. 1954. Postharvest physiology of fruits and vegetables. Annu. Rev. Plant Physiol. 5:205-224.

Raison, J.K. and G.R. Orr. 1990. Proposals for a better understanding of the molecular basis of chilling injury, p. 145-164. In: C.Y. Wang (ed.). Chilling injury of horticultural crops. CRC Press, Boca Raton, FL.

Rikin, A., D. Atsmon, and C. Gitler. 1979. Chilling injury in cotton: Prevention by abscisic acid. Plant Cell Physiol. 20:1537-1546.

Rikin, A. and A.E. Richmond. 1976. Amelioration of chilling injuries in cucumber seedlings by abscisic acid. Physiol. Plant. 38:95-97.

Schiffmann-Nadel, M., E. Chalutz, J. Waks, and F.S. Lattar. 1972. Reduction of pitting of grapefruit by thiabendazole during long-term cold storage. HortScience 7:394-395.

Senaratna, T., C.E. Mackay, B.D. McKersie, and R.A. Fletcher. 1988. Uniconazole-induced chilling tolerance in tomato and its relationship to antioxidant content. J. Plant Physiol. 133:56-61.

Shewfelt, R.L. 1992. Response of plant membranes to chilling and freezing, $p$. 192-219. In: Y.Y. Leshem (ed.). The plant membrane: A biophysical approach. Kluwer Press, Amsterdam.

Wade, N.L. 1979. Physiology of cool-storage disorders of fruits and vegetables, p. 81. In: J.M. Lyons, D. Graham, and J.K. Raison. (eds.). Low temperature stress in plants. Academic, New York.

Wang, C.Y. 1982. Physiological and biochemical responses of plants to chilling stress. HortScience 17:173-186.

Wang, C.Y. 1991. Effect of abscisic acid on chilling injury of zucchini squash. J. Plant Growth Regulat. 10:101-105.

Wang, C.Y. and J.E. Baker. 1979. Effects of two free radical scavengers and intermittent warming on chilling injury and polar lipid composition of cucumber and sweet pepper fruits. Plant Cell Physiol. 20:243-251.

\title{
Response of Tropical Horticultural Commodities to Insect Disinfestation Treatments
}

\author{
Robert E. Paull \\ Department of Plant Molecular Physiology, College of Tropical Agriculture and Human Resources, University of \\ Hawaii at Manoa, 3190 Maile Way, Honolulu, Hawaii, 96822
}

Postharvest treatments are required to disinfest fresh fruits, vegetables, and flowers of economically important quarantined insects. The damage caused by such insects includes small surface blemishes, destruction of the edible flesh, fruit drop, and spoilage from decay organisms entering the fruit at the site of insect activity (Hagen et al., 1981). These insect pests are of quarantine importance because they are absent from the importing country or region, or the importing country has a "zero tolerance" for all live insects regardless of their economic importance (Armstrong and Couey, 1989). Monitoring insect populations and having regulatory personnel inspect commodities are required to ensure that quarantine treatment protocol and regulations are carried out properly, including proper handling to preclude reinfestation after treatment. Failure to apply disinfestation protocols correctly can result in expensive quarantine and eradication procedures, product losses due to infestation, and costly new quarantine treatments due to introduction of a new pest (Armstrong, 1992). Recent outbreaks of Mediterranean fruit flies in California atest to these failures.

Expansion of world trade in fresh horticultural products has compounded problems associated with regulating quarantine treatments.
The expansion of international passenger traffic and short transit times has meant repeated violations of quarantine barriers. The greatest risk may be associated with contraband fruit smuggled by airline passengers rather than commercial fruit shipments. For example, a 1-week inspection "blitz" during May 1990 of all passenger baggage coming through Los Angeles International Airport from selected Central and South American countries resulted in 677 interceptions of contraband fruit. The total weight seized was almost $1 \mathrm{t}$ and contained 61 fruit fly larvae. This contrasts with the average interception rate of 434 contraband fruit per week with random baggage inspections of all international arrivals.

The reproduction rate, short life cycle, and adaptability of pest insects, as well as their destructive potential, underscore the need for quarantine treatments and regulatory and physical barriers (Carey and Dowell, 1989; Mitchell and Saul, 1990). The reproduction rates for many insects of quarantine importance are rapid, especially under optimum conditions, including moderate to high temperatures and the absence of low winter temperatures (Fletcher, 1987). The time required for life cycle completion differs with environmental factors and species. Development times are similar for all fruit fly species: egg, 1- 